\title{
Move Structures and Cognitive Genres in the Methods Sections of Experimental Research Articles and Corpus-Based Studies in Applied Linguistics
}

\author{
Weichen Chuang ${ }^{1} \&$ Chia-Chi Chen ${ }^{2}$ \\ ${ }^{1}$ Department of Applied Foreign Languages, Shih Chien University, Taipei, Taiwan \\ ${ }^{2}$ Doctoral Program of Educational Leadership and Technology Management, Tamkang University, New Taipei \\ City, Taiwan \\ Correspondence: Weichen Chuang, Department of Applied Foreign Languages, Shih Chien Uuniversity, No.70, \\ Dazhi St., Zhongshan Dist., Taipei 104, Taiwan. E-mail: weichenchuangatshihchien@gmail.com
}

Received: September 8, $2020 \quad$ Accepted: October 12, $2020 \quad$ Online Published: October 29, 2020

doi:10.5539/ijel.v11n1p10 URL: https://doi.org/10.5539/ijel.v11n1p10

\begin{abstract}
This paper reports an investigation of the variation in the move structures and cognitive genres found in the methods sections of research articles (RAs) in a discipline with diversified research methods. Sixty-five RAs involving two research methods in applied linguistics, namely corpus-based studies and experimental research, were analyzed. The results showed that the methods sections of these RAs contained distinct move structures. These distinct move structures, along with the findings of previous studies on the move structures of various disciplines, suggested that the research method adopted in a study is a stronger factor than discipline is in determining the move structure of the methods section. The analysis of the cognitive genres used in the methods sections showed that authors typically require more than one cognitive genre to realize the major moves of the methods sections. However, this variation in the cognitive genres is low between the two patterns of study. These findings suggested that different research methods yield variations in the move structures of the methods sections. However, the cognitive genres that authors require to realize the move structures tend to be common.
\end{abstract}

Keywords: methods sections, genre, move structures, cognitive genre, English for academic purposes

\section{Introduction}

A research article (RA) is an argument that aims to convince the readers that the knowledge claims proposed by the author are acceptable. The methods section of a RA plays a crucial rhetorical role in this persuasive speech of action. It describes the means through which the findings were obtained and validates them. Although the method section is necessary for providing crucial methodological information and is an essential logical link in the presented argument, few studies have reported on it. Only a few researchers have detailed the move structure of the methods section in a RA in the past ten years (Swale \& Luebs, 2002; Kanoksilapatham, 2005; Lim, 2006; Peacock, 2011; Kanoksilapatham, 2015).

The longstanding tendency of downplaying the importance of the methods sections might have partially contributed to the long-held belief, first published by Swales (1990), that the methods sections in science RAs are becoming de-emphasized and concise, which may lead EAP scholars to believe that the methods sections, at least those of science RAs, are less crucial than other sections are and that they do not deserve much attention. However, this may not be true. Peacock (2011) mentioned that Swale's claim was based on the observation of a low number of RAs. In addition, Peacock cited Glenhill (2000) to question the assertion that the methods sections are less crucial. Gledhill examined 150 RAs on cancers and reported that the methods sections of these RAs constituted $32 \%$ of the total length of the texts, suggesting that the methods sections are not short and de-emphasized, at least in medical RAs on cancer. Moreover, Peacock (2011) found that the methods sections in RAs across eight disciplines including physics, biology, chemistry, environmental science, business, language and linguistics, law, and public and social administration constitute $25 \%$ of the total length of RAs, supporting the importance of the methods sections. Peacock is not alone on his stand on the significance of methods sections of RAs; Lim (2006) and Kanoksilapatham (2005) also called for the study of the generic structure of the methods sections in RAs, which they believed was under-researched. 
Although scholars differ in their views on the importance of the methods sections in science RAs, they agree that the structure of the methods section varies across disciplines. Moves were the central concept used for analyzing the varied generic structure of the methods sections of many studies. Moves are a structural device of rhetoric through which the text is built systematically to aid communication in a staged or sequential manner. A move may contain several steps. According to Swales (1990), not all moves and steps are obligatory, and their sequence may vary; a move or a step can be repeated and may be embedded within each other (p. 58). Move analyses of the methods sections in various disciplines supported the claim that the generic structure of the methods section varies widely (Lim, 2006; Peacock, 2011; Kanoksilapatham, 2015). The findings of the previous studies revealed that the methods sections in science and engineering RAs share three basic moves: describing materials, describing procedure, and data analysis (Kanoksilapatham, 2007; Peacock, 2011; Kanoksilapatham, 2015). Although describing procedure and data analysis are also the most common moves in the methods sections of social sciences RAs, including those of language and linguistics, law, public and social administration, business, and management (Lim, 2006; Peacock, 2011), the methods sections in social sciences RAs tend to have more moves than those in most science and engineering RAs, except those of environmental sciences (Peacock, 2011). The additional moves in the methods sections of social sciences RAs were location, limitation, research aims/questions/hypotheses, and overview. This variation in moves in the methods sections of engineering and science RAs and the social sciences RAs confirm the disparity in the move structure in "hard" and "soft" sciences.

In contrast to the widely investigated variation in move structures across disciplines, variation in move structures existing within a discipline has rarely been addressed. In social sciences such as applied linguistics, multiple research designs have been employed for collecting data through various means for different research purposes. For an applied linguist studying the foreign language learning attitudes of a certain group of learners, an appropriate research design is a survey. By contrast, an applied linguist studying the linguistic features of legislative provisions prefers a corpus-based study than a survey. Different research designs involve explaining and detailing different methodological considerations, thus possibly resulting in the use of different move structures in RAs. For example, the move structures of quantitative survey designs of the methods sections of applied linguistic RAs may have limited applicability to the methods sections of corpus-based studies.

It has been pointed out that applied linguists use multiple methods, including various quantitative and qualitative research methods (Collin-Kies, 2014). Therefore, it is highly possible that that multiple models are required to describe the move structures of in RAs in applied linguistics RAs. However, although it is acknowledged that there is a great diversity of the various research methods employed by applied linguistics, the possible impacts of this methodological diversity on the move structures of in RAs in applied linguistics RAs have rarely been investigated. Peacock's study introduced four common moves of in the methods sections of language and linguistics RAs: subjects/materials, location, procedure, and data analysis. This model is advantageous because it is broad and applicable to any field in language, linguistics and social sciences. However, it does not provide specific information on what should be included in each move. Thus, the advantage of the model is also a limitation in providing practical guidance to student RA writers. Until now, few studies have investigated the moves and steps of RAs employing research methods other than surveys and experiments. To effectively assist student writers adopt various research methods, the diversity of research methods within a discipline should be a research topic for EAP scholars conducting move analysis on RAs.

\subsection{Cognitive Genres}

Move analysis has been a central topic of studies on academic writing. As mentioned in the previous section, move analysis focuses on the rhetorical structure of a genre. An academic writer requires the knowledge of the rhetorical structure of a genre to accomplish a writing task. In addition, the writer requires another type of compositional knowledge that is cognition oriented. This cognition-oriented knowledge enables a writer to compose various types of text in order to execute each move of a genre. Genre and text types may appear similar but are essentially different. Genre refers to a "message type" that is widely recognized in a specific discourse community, such as a business memo and a research article. Genre is largely a social phenomenon. By contrast, text types are cognition oriented and are described in categories, such as description, explanation, and recount (Knapp \& Watkins, 2005). A writer uses text types to realize a genre, such as complaint letters. A piece of written work, such as a research paper, is usually realized by multiple uses of various text types. Different terms have been developed to refer to genres and text types. For example, Pilegaard and Frandsen (1996) used text genres to refer to genres without developing another term for text types. Although the terms used vary, they share similar ideas. Furthermore, to master the skills of academic writing, students need both genre knowledge - knowledge of the recurrent content-organizing patterns of a genre - and text-type knowledge - the awareness of the major text 
types and the ability to compose texts of each text type (Paltridge, 2002; Bruce, 2005; 2008).

Bruce (2005) used "cognitive genres" to refer to text types. According to Bruce (2009), cognitive genres are "complex organizational categories that are usually drawn upon in combination when creating whole texts. They are described in terms of a model that draws upon cognitive, rather than social, or linguistic knowledge" (p. 107). On the basis of the four text types characterized by Biber (1989), Bruce proposed models for four cognitive genres that commonly occur in academic English prose. The models are listed in Table 1.

Table 1. Summary of the cognitive genre model

\begin{tabular}{|c|c|}
\hline \multicolumn{2}{|c|}{ Report: static descriptive presentation } \\
\hline Rhetorical focus & Presentation of data that is essentially not-sequential \\
\hline Gestalt structure & WHOLE PART structure of which PART has as UP DOWN structure \\
\hline Discourse pattern & Preview-details \\
\hline Interpropositional relations & $\begin{array}{l}\text { Amplification; reason-result, grounds-conclusion; simple contrast, simple comparison, } \\
\text { concession-contra expectation, condition-consequence }\end{array}$ \\
\hline \multicolumn{2}{|c|}{ Explanation: means-focused presentation } \\
\hline Rhetorical focus & The presentation of information with the orientation on means \\
\hline Gestalt structure & SOURCE PATH GOAL schema: LINK schema \\
\hline Discourse pattern & Preview-details \\
\hline Interpropositional relations & Means-purpose, means-result, amplification, concession-contra expectation \\
\hline \multicolumn{2}{|c|}{ Discussion: choice/outcome-focused presentation } \\
\hline Rhetorical focus & Focus on the organization of data in relation to (possible) outcomes/conclusions/choices \\
\hline Gestalt structure & CONTAINER schemata (more than one) \\
\hline Discourse pattern & Generalization-examples and matching \\
\hline Interpropositional relations & Grounds-conclusion, reason-result, means-purpose, means-result, concession-contra expectation \\
\hline \multicolumn{2}{|c|}{ Recount: sequential presentation } \\
\hline Rhetorical focus & Presentation of data or information that is essentially sequential or chronological \\
\hline Gestalt structure & SOURCE PATH GOAL schema \\
\hline Discourse pattern & General-particular, problem solution \\
\hline Interpropositional relations & $\begin{array}{l}\text { Means-purpose, means-result, amplification, chronological sequence, grounds-conclusion, } \\
\text { reason-result }\end{array}$ \\
\hline
\end{tabular}

Source: Bruce, 2008, p. 43; 2005, p. 245.

Each model in the table has a rhetorical focus that relates to a general rhetorical goal, which targets a certain type of knowledge intended to be communicated. In addition, each model has an internal structure that includes three levels: gestalt structure, discourse pattern, and interpropositional relations.

Gestalt structures refer to the organization of the concepts or ideas in relation to the organization of the entire text. They are the "WHOLE-PART structure of which PART has an UP DOWN structure." Discourse patterns refer to textual patterns, which tend to co-occur in a cognitive genre. Examples of discourse patterns are general-particular, problem-solution, and preview-details. Interpropositional relations refer to the relation between two propositions: means-purpose and reason-result. Each cognitive genre is characterized by several interpropositional relations with high frequencies. As Bruce (2008) stated, interpropositional relations directly affect the linguistic selection related to cohesion and coherence.

Bruce developed models on the basis of the theories of cognitive science (2008). The models are hierarchical in nature because of the cognitive relations among the levels constituting them; the upper levels influence the lower levels. In other words, the rhetorical focus of a given text engages a specific gestalt structure, which leads to the engagement of specific discourse patterns and eventually affects the interpropositional relations within the text.

Bruce (2008) used cognitive genre structures for analyzing the methods sections in RAs and revealed that the methods sections of RAs of hard sciences and engineering (e.g., chemistry, pediatrics, and chemical engineering) tended to use a means-focused discourse structure, whereas those in RAs of soft sciences and social sciences (e.g., education, applied linguistics, and sociology) employed a combined chronological and nonsequential descriptive structure.

Because most social sciences studies are quantitative studies that use surveys and experiments for data collection, the major cognitive genres of the methods sections of social sciences RAs identified by Bruce may have been the major cognitive genres employed in the methods sections that describe the research designs of surveys and experiments. However, as mentioned previously, RAs of social sciences such as applied linguistics have multiple 
research methods. The findings by Bruce may have limited applications to applied linguistics RAs employing a research design that is not an experiment or survey.

Another limitation is that Bruce studied the cognitive genres of the methods sections in which the cognitive genres were independent of the rhetorical structures of the methods sections. Bruce analyzed each text of the methods sections as a single unit; he did not segment the text into several units based on the rhetorical structure. Because each rhetorical structure unit (e.g., a move in the methods section of a RA) has its own communicative goal, numerous cognitive genres and different combinations of cognitive genres may be required to achieve the different communicative goals.

This study therefore, analyzed the move structures of two research methods, namely corpus-based discourse analysis and experimental studies in applied linguistics and examined the cognitive genres used in each move of the move structures in the two research methods.

\section{Method}

\subsection{Corpus}

The corpus used in this study contained two subcorpora, a subcorpus of the methods sections of experimental RAs and a subcorpus of the methods sections of corpus-based RAs.

Five applied linguistics professors were consulted to compile a list of leading journals of applied linguistics containing sufficient experimental research and corpus analysis RAs from which the sample articles were selected. The top journals in TESOL and applied linguistics listed by Egbert (2007) were used as a guideline for journal selection. As a result, six journals were selected as the source from which the methods sections of the experimental RAs were selected: TESOL Quarterly, Journal of Second Language Writing, Studies in Second Language Acquisition, Modern Language Journal, Language Learning, and Applied Linguistics. Seven journals were selected as the source of the sample articles of corpus-based studies: TESOL Quarterly, Journal of Second Language Writing, Modern Language Journal, Language Learning, Applied Linguistics, English for Specific Purposes, and Journal of English for Academic Purposes. All these journals are indexed in the SSCI. English for Specific Purposes and Journal of English for Academic Purposes were included in the list of the journals of corpus-based research and not in the list of the journals of experimental research because a corpus-based approach has been the major research approach of ESP/EAP studies. These two journals comprise numerous high-quality corpus-based RAs. However, they have very few experimental RAs. By contrast, Studies in Second Language Acquisition has many high-quality experimental RAs and few corpus-based studies. Thus, this journal was not included in the list of the journals of the corpus-based studies because it has extremely few corpus-based studies compared with the other journals in the list. Five articles were randomly selected from each journal from the issues published between 2008 and 2014. Consequently, the subcorpus of the methods sections of experimental RAs contained 30 texts with approximately 51,000 running words and that of the methods sections of corpus-based RAs contained 35 texts with approximately 48,000 running words (Note 1).

Because the articles were published in leading applied linguistics journals, the level of English in these articles was assumed to match the required proficiency levels of these journals. Thus, the English nativeness of the authors was not considered. Although "experimental research" and "corpus-based study" may appear to designate two distinctive types of research, an experimental design may incorporate a corpus analysis. In this study, such designs were categorized as experimental research, and corpus-based studies are exclusively those that analyze linguistic data contained in a corpus or corpora without any experimental treatment involved in the research designs.

\subsection{Data Analysis}

Based on the findings of Peacock (2011) and Lim (2006), the researcher together with the other coder, a research assistant who has a Master degree in TESOL, first coded five texts randomly selected from the experimental RAs corpus and another five from corpus-based RAs corpus to develop a coding prototype for the RAs of each research type. The primordial coding systems were then applied to the moves and steps coding of the rest of the texts, which was conducted independently by the author and the research assistant. Percentage agreement was computed to assess the inter-coder reliability. The results were summarized in Table 2: 
Table 2. Summary table of inter-coder reliability analysis of the moves and the steps of the two types of RAs

\begin{tabular}{lllll}
\hline Rhetorical Unit & Coded Unit & Agreement & Disagreement & Percent \\
\hline Moves (experiment) & 92 & 84 & 8 & 91.30 \\
Steps (experiment) & 297 & 246 & 51 & 82.82 \\
Moves (corpus) & 83 & 83 & 0 & 100 \\
Steps (corpus) & 185 & 154 & 31 & 83.24 \\
Total Units/Average Percent & Moves: 175 & Moves: 167 & Moves: 8 & Moves: 95.42 \\
& Steps: & Steps: & Steps: & Steps: \\
& 482 & 400 & 82 & 82.98 \\
\hline
\end{tabular}

The results showed a high agreement on identifying the moves and the steps.

Except a few coding errors, most of the disagreements appeared to be different opinions of the two coders on whether a segment should be divided into two different steps. Differences in the coding were discussed, negotiated and resolved.

Similar to Lim's study (2006), the two coders identified the boundaries of moves and steps with reference to markers such as typographical features and linguistic clues commonly used in the texts. However, it was unity of a segment that determined whether it was coded as a unit in the move analysis.

The cognitive genre model proposed by Bruce (2005) was adopted as the theoretical framework for the cognitive genre analysis. This model was considered appropriate for analyzing the text types of the RAs because the four cognitive genres identified by Bruce are commonly observed in academic English prose (Bruce, 2005, 2009, 2010).

All texts were coded independently by the author and the research assistant. The percentage agreement of the cognitive genre coding was calculated. The results were shown in Table 3.

Table 3. Summary table of inter-coder reliability analysis of the cognitive genres of the two types of RAs

\begin{tabular}{lllll}
\hline RA Types & Coded Unit & Agreement & Disagreement & Percent \\
\hline Experimental RAs & 202 & 191 & 11 & 94.55 \\
Corpus-based RAs & 151 & 134 & 17 & 88.74 \\
Total Units/Average Percent & 353 & 325 & 28 & 92.06 \\
\hline
\end{tabular}

Note. ${ }^{*}$ The unit used for the identification of cognitive genres was paragraph.

The results showed that the cognitive genre of each paragraph in the texts was reliably identified by the two coders.

Almost all of the disagreements occurred in the identification of one paragraph as an Explanation or a Recount. Similar to the process of the move analysis, differences in the coding appeared in the cognitive genre analysis were discussed and resolved.

\section{Results and Discussion}

\subsection{Move Structures of the Methods Sections}

The move analysis of the methods sections of the experimental and corpus-based RAs indicated that the two patterns of research yielded distinct moves and steps in the methods sections. The necessary moves in the methods sections of the experimental RAs were describing participants and describing data collection while those of corpus-based studies were describing the corpus and elucidating data analysis procedure(s) (Table 4).

Table 4. Summary table of inter-coder reliability analysis of the moves and the steps of the two types of RAs

\begin{tabular}{|c|c|c|c|c|c|}
\hline \multirow[t]{2}{*}{ Move/step } & \multirow{2}{*}{$\begin{array}{l}\begin{array}{l}\text { Experimental } \\
\text { studies }(\mathrm{N}=30)\end{array} \\
\text { Results } \\
\end{array}$} & \multirow[b]{2}{*}{ Percent } & \multirow[t]{2}{*}{ Move/step } & \multirow{2}{*}{$\begin{array}{l}\text { Corpus-based } \\
\text { studies }(\mathrm{N}=35) \\
\text { Results } \\
\end{array}$} & \multirow[b]{2}{*}{ Percent } \\
\hline & & & & & \\
\hline Move 1: Describing participants & $30 / 30$ & 100.00 & $\begin{array}{l}\text { Move 1: Providing information of } \\
\text { the corpus }\end{array}$ & $35 / 35$ & 100.00 \\
\hline $\begin{array}{l}\text { Detailing location, sample size } \\
\text { and language-related features }\end{array}$ & $30 / 30$ & 100.00 & $\begin{array}{l}\text { Describing quantity, source, and range } \\
\text { of the linguistic data }\end{array}$ & $35 / 35$ & 100.00 \\
\hline $\begin{array}{l}\text { Specifying grouping procedure or } \\
\text { grouping results }\end{array}$ & $18 / 30$ & 60.00 & $\begin{array}{l}\text { Presenting the text selection criteria } \\
\text { (process)/or genre selection. Or } \\
\text { rationale of the corpus compiling }\end{array}$ & $18 / 35$ & 51.43 \\
\hline
\end{tabular}




\begin{tabular}{|c|c|c|c|c|c|}
\hline Describing other participants & $7 / 30$ & 23.00 & Providing background information & $7 / 35$ & 20.00 \\
\hline Describing setting & $4 / 30$ & 13.33 & Presenting an overview of the design & $1 / 35$ & 2.86 \\
\hline Recounting recruitment & $2 / 30$ & 6.67 & & & \\
\hline $\begin{array}{l}\text { Move 2: Providing information } \\
\text { about target features }\end{array}$ & $12 / 30$ & 40.00 & & & \\
\hline Describing target features & $9 / 30$ & 30.00 & & & \\
\hline $\begin{array}{l}\text { Explaining the reasons for } \\
\text { choosing this/these target } \\
\text { feature(s) }\end{array}$ & $8 / 30$ & 26.67 & & & \\
\hline $\begin{array}{l}\text { Explaining means to identify the } \\
\text { target feature(s) }\end{array}$ & $1 / 30$ & 3.33 & & & \\
\hline $\begin{array}{l}\text { Move 3: Describing data } \\
\text { collection procedure(s) }\end{array}$ & $30 / 30$ & 100.00 & $\begin{array}{l}\text { Move 2: Describing data collection } \\
\text { procedure(s) }\end{array}$ & $13 / 35$ & 37.14 \\
\hline $\begin{array}{l}\text { Presenting an overview of the } \\
\text { design }\end{array}$ & $16 / 30$ & 53.33 & Detailing data collection procedure & $12 / 35$ & 34.29 \\
\hline $\begin{array}{l}\text { Describing materials/tasks used in } \\
\text { the data collection process }\end{array}$ & $30 / 30$ & 100.00 & Justifying the procedure/means & $1 / 35$ & 2.86 \\
\hline $\begin{array}{l}\text {-Specifying } \\
\text { instructional/experimental } \\
\text { procedure(s)* }\end{array}$ & $21 / 30$ & 70.00 & & & \\
\hline -Detailing materials/tasks/stimuli & $13 / 30$ & 43.33 & & & \\
\hline $\begin{array}{l}\text {-Specifying administration of the } \\
\text { tasks }\end{array}$ & $16 / 30$ & 53.33 & & & \\
\hline $\begin{array}{l}\text {-Explaining development of the } \\
\text { materials/tasks }\end{array}$ & $13 / 30$ & 43.33 & & & \\
\hline $\begin{array}{l}\text {-Justifying the use of the } \\
\text { materials/tasks }\end{array}$ & $4 / 30$ & 13.33 & & & \\
\hline $\begin{array}{l}\text { Explaining method(s) measuring } \\
\text { variables }\end{array}$ & $30 / 30$ & 100.00 & & & \\
\hline $\begin{array}{l}\text {-Specifying items in } \\
\text { questionnaires }\end{array}$ & $17 / 30$ & 56.67 & & & \\
\hline $\begin{array}{l}\text {-Specifying administration of the } \\
\text { measurement }\end{array}$ & $20 / 30$ & 66.67 & & & \\
\hline $\begin{array}{l}\text {-Detailing methods of } \\
\text { scoring/rating/coding }\end{array}$ & $18 / 30$ & 60.00 & & & \\
\hline $\begin{array}{l}\text {-Explaining development of the } \\
\text { measurement }\end{array}$ & $5 / 30$ & 16.67 & & & \\
\hline $\begin{array}{l}\text {-Justifying the measurement } \\
\text { through citing previous studies }\end{array}$ & $4 / 30$ & 13.33 & & & \\
\hline $\begin{array}{l}\text {-Justifying the measurement } \\
\text { through providing information on } \\
\text { reliability and validity }\end{array}$ & $10 / 30$ & 33.33 & & & \\
\hline $\begin{array}{l}\text { Move 4: Elucidating data } \\
\text { analysis procedure(s) }\end{array}$ & $20 / 30$ & 66.67 & $\begin{array}{l}\text { Move 3: Elucidating data analysis } \\
\text { procedure(s) }\end{array}$ & $35 / 35$ & 100.00 \\
\hline \multirow[t]{8}{*}{ Explaining statistical analysis } & $20 / 30$ & 66.67 & $\begin{array}{l}\text { Stating theoretical/method model or } \\
\text { the conceptual framework }\end{array}$ & $12 / 35$ & 34.29 \\
\hline & & & $\begin{array}{l}\text { Explaining the linguistic features to } \\
\text { be analyzed OR the means to identify } \\
\text { the target features OR a combination } \\
\text { of the two }\end{array}$ & $21 / 35$ & 60.00 \\
\hline & & & Introducing the concordancing tool(s) & $19 / 35$ & 54.29 \\
\hline & & & $\begin{array}{l}\text { Providing the information on the } \\
\text { inter-rater reliability }\end{array}$ & $3 / 35$ & 8.57 \\
\hline & & & $\begin{array}{l}\text { Specifying the procedure of the data } \\
\text { analysis }\end{array}$ & $35 / 35$ & 100.00 \\
\hline & & & Justifying the data procedure(s) & $3 / 35$ & 8.57 \\
\hline & & & $\begin{array}{l}\text { Specifying additional steps of the data } \\
\text { analysis procedure(s) (e.g. grading, } \\
\text { coding) }\end{array}$ & $3 / 35$ & 8.57 \\
\hline & & & Presenting the research questions & $2 / 35$ & 5.71 \\
\hline
\end{tabular}

Note. *The steps begin with a "." are "sub-steps" of a step, which share the common communicative goals of this step at the upper conceptual level.

Data analysis and data collection were found in each full text of the RAs reviewed. However, although data analysis was a necessary move in the methods sections of corpus-based RAs, it was not a necessary move in those of the experimental RAs. A few authors of experimental RAs on the corpus preferred to exclude data 
analysis from the methods sections and integrate it with the research findings to form the results section, indicating that although both patterns of RAs may contain the move of data analysis, experimental RAs allow more flexibility regarding the location of the move.

Unlike data analysis, which was necessary in both the investigated research designs, only $38 \%$ of the studied corpus-based RAs contained data collection, whereas it was indispensable for the methods sections of the experimental RAs; this was an expected finding. Because the goal of an experiment is to test a cause-effect relationship in an experimental design, the study subjects receive an experimental treatment through which data relevant to the research questions are obtained in order to test the cause-effect relationship between the treatment and the desired effect(s). Thus, data collection is a mandatory move in the methods sections of experimental RAs through which an author describes the data collection methodology to convince the readers that the data collected for analysis are appropriate and accurate. By contrast, most corpus-based studies are descriptive research. There may be existing linguistic data that are available for analysis; these data need not be generated in an experimental process as they are in experimental designs. As corpus-based RAs with data collection were studies with designs to generate linguistic data and constituted only $38 \%$ of the studied corpus-based RAs, this suggests that most corpus linguistics may prefer existing linguistic data over linguistic data generated through the processes of their own designs.

\subsection{Basic Moves and Major Steps in the Methods Sections of Experimental RAs (Note 2)}

Two types of moves were labeled in the study: basic and optional moves. Basic moves are those found commonly in all examined texts, conveying essential information pertaining to the research design or pattern. Optional moves are those found in certain texts, containing information that is idiosyncratic to a subset of a specific research pattern or design. The move analysis showed that the methods sections of the experimental RAs contained two basic moves, describing participants and describing data collection, and two optional moves, target features and data analysis.

Each basic move contained its own major step(s) (Note 3). The most frequently observed step in describing participants was providing the basic information of the sample, in which the information regarding the location at which the participants received the experimental treatment, the sample size, and the language-related features of the participants were included. All reviewed experimental RAs contained this step. Grouping was another major step in the move, and 18 of the 30 reviewed experimental RAs contained this step. These steps were present in the experimental research texts because the elements described in these steps are the essentials of a research design. Unlike these essentials, the elements described in other steps (e.g., participant recruitment) were only appropriate to certain designs.

In describing data collection, two steps were found to be included in all texts of the experimental RAs: describing the tasks/materials employed in the data collection process and explaining measuring variables. To describe the tasks/materials employed in the data collection process, writers usually included the instructional or experimental procedure and the task administration. Some writers detailed the descriptions of the materials and tasks. If materials or tasks were developed particularly for the research, the writer included a description of the development of the materials or tasks. Moreover, only one in seven writers included a paragraph to justify the use of the materials or tasks, suggesting that for most writers, the description of the materials or tasks alone is sufficient to support the appropriateness of their employment.

In explaining method(s) measuring variables, writers usually included the content and purpose of the measurements and their administration and scoring; these were the basics included in the step. Writers who developed their own measurements included the development of the measurements in this step. In addition, the measurements were justified in some texts. In one-third of the experimental RAs, the reliability and validity of the measurements were included to justify their use, and approximately one-fifth referred to relevant studies to support their adoption of the measurements in their studies. The finding that not all writers provided justifications of the measurements may be attributed to the nature of the studies in the field of applied linguistics. In quantitative studies, a tool must be developed to measure something that cannot be directly observed. In this case, the validity and the reliability of the tool are essential for yielding valid data. However, unlike studies in psychology, which measure the psychological characteristics that are not directly observable, applied linguists may study language learner behaviors, which are observable (e.g., frequency of the use of reported speech), and linguistic competency, which is not directly observable (e.g., general reading comprehension). A detailed description of the "what" and "how" of the calculation is sufficient to justify the calculation of the frequencies of the directly observable language learner behaviors. This may explain why a distinct justification of the measurement was not found in all texts analyzed in this study. 


\subsection{Basic Moves and Major Steps in the Methods Sections of Corpus-Based RAs}

Three moves, providing the information of the corpus, describing data collection process, and elucidating data analysis procedure(s) were identified through the move analysis of the methods sections of corpus-based RAs. Among the three moves, providing the information of the corpus and elucidating data analysis procedure(s) occurred in all examined texts; these two are the basic moves of the methods sections in corpus-based RAs. Each essential move has major and minor steps. The major steps of providing the information of the corpus were describing quantity, source, and range of the linguistic data of the corpus and presenting the text selection criteria (process) or rationale of the corpus compiling. The minor steps were providing background information and presenting an overview of the corpus, which occurred in no more than seven texts reviewed in the study. The two major steps of the move presented the audience with goals of compiling the corpus, the rationale behind compiling the corpus, and the compilation results; these are exactly what authors are expected to provide to support what they performed.

The major steps of elucidating data analysis were explaining the linguistic features to be analyzed, introducing the concordancing tool(s), and specifying the procedure of the data analysis. Although these steps were observed frequently, they were not mandatory except the procedure of the data analysis. Take introduction of the concordancing tools for example. Although corpus-based studies often involve concordancing tools, a few studies do not require them. Studies of move analysis, for example, do not involve the employment of concordancing tools. Thus, not all corpus-based RAs contain the descriptions of concordancing tools.

Five minor steps were found in the move describing data analysis. Among them, explaining the theoretical/methodological model of analysis occurred most often in the study. Particularly, it occurred in one-third of the examined corpus-based studies. This step provides a theoretical base for the analytic procedure performed in a study. Although only one-third of the authors of the studied corpus-based RAs included elaborate details of this step, its methodological importance may not be less significant than that of the concordancing tools, particularly when the study is highly theoretical.

\subsection{Move Structures of the Methods Sections of Various Disciplines}

Although the move and step structures of the methods sections of management RAs reported by Lim (2006) may not be exactly the same as the results of the move analysis of the experimental RAs of the current study, the two bears striking resembles on closer examination. Both studies have four common major moves or steps: describing the sample/participants, recounting the steps in data collection/describing the data collection procedures, explaining method(s) of measuring variables and elucidating data analysis procedure(s). The difference lies in the ways of categorization of the steps into various moves. Lim classified describing the sample and recounting steps in data collection as one move, whereas in this study, describing the sample was considered an independent move.

Furthermore, these basic moves and steps of the methods sections of management and experimental applied linguistics RAs even share two common moves or steps with those of science and engineering RAs. According to Kanoksilapatham (2007), Peacock (2011), and Kanoksilapatham (2015), describing materials/participants, detailing data collection procedure(s) and describing statistical procedures (data analysis in Peacock's term) are commonly found in the methods sections of science and engineering RAs, which are similar to describing participants, describing data collection procedures and elucidating data analysis, the three basic moves of experimental applied linguistic RAs.

The findings of the study show that the move and step structures of the methods sections of applied linguistics RAs involving experimental designs share significant commonalities with those of management RAs and science and engineering RAs. This may be expected because survey and experiments, the two basic designs of quantitative studies, are the major research designs most frequently used in management and science and engineering. The methods sections of experiment-based applied linguistic RAs, management RAs, and science and engineering RAs should share similar communicative goals, which requires move structures with commonalities to reach these homogeneous communicative goals. By contrast, the move analysis of the methods sections of corpus-based RAs showed that the basic moves of the methods sections of corpus-based RAs shared lower similarities with those of management RAs than experiment-based applied linguistic RAs did (the most common moves of corpus-based RAs were describing the corpus and data analysis). This indicates that the method designs rather than the disciplines matter in determining the basic moves and steps in the methods sections of RAs. 


\subsection{Cognitive Genres Employed in the Methods Sections}

The cognitive genres of the paragraphs of the basic moves and the essential steps were studied. In contrast to the distinct move structures of the methods sections that the experimental and corpus-based RAs have, the cognitive genres employed to realize the methods sections of the two patterns of research do not differ. The methods section in experimental and corpus-based RAs can be composed through the sophisticated combination of three basic cognitive genres of academic writing: explanation, report, and recount.

\subsection{Cognitive Genres Employed in the Methods Sections of Experimental RAs}

The cognitive genre that occurred most frequently in the methods sections of experimental RAs was explanation, followed by report. In the subcorpus, 115 of 202 paragraphs in the major steps in the basic moves were identified as explanation and 68 as report. In other words, 57\% were explanation and 34\% were report. Only 19 paragraphs $(9 \%)$ were identified as recount. Table 5 is a cross-reference table that summarizes the analysis of the cognitive genres of the basic moves and essential steps in the studied experimental RAs.

Table 5. Cognitive genres of the basic moves and essential steps in the methods sections of experimental RAs

\begin{tabular}{ll}
\hline Moves/Steps & Number of paragraphs identified as a cognitive genre \\
\hline Move 1: Describing participants & \\
$\begin{array}{l}\text { Detailing location, sample size, and language-related features } \\
\text { Specifying grouping process or grouping results }\end{array}$ & Rp30 \\
Move 3: Describing data collection procedure(s) & Exp:15; Rp:5 \\
Presenting an overview of the design & Exp: $12 ;$ Rp:3: Rec: 1 \\
Describing materials/tasks used in the data collection process & Exp:35; Rec:15: Rp: 13 \\
Explaining measurement & Exp: $35 ;$ Rp:17: Rec: 3 \\
Move 4: Elucidating data analysis (Note 4) & Exp: 20 \\
\hline
\end{tabular}

In addition, the analysis showed that the cognitive genres employed to realize a move or a step correlated with the communicative goals of the move or the step. For instance, the goal of the step location, sample size, and language features in the move participants was to provide the relevant features of the sample to support the appropriateness of the sample. The adoption of report is required to accomplish such a task. Conversely, the step the administration of the task in the move data collection describes the manner in which the task was conducted. Therefore, the cognitive genres that the writers required to accomplish this task were explanation and recount.

Because the cognitive genres employed to realize a step should enable the accomplishment of its communicative goals, the cognitive genres observed in one step are able to organize information of similar nature in various forms. For instance, explanation and recount were both found to occur frequently in the step instructional/ experimental procedure in the move data collection. Although explanation emphasizes the means-focused presentation and recount emphasizes the sequential presentation, both are able to organize chronological information, and these two cognitive genres are reasonable choices for a writer working on administration of the task.

Some cognitive genres constituting one step did not share similarities in organizing information. The step of grouping in the move participants was realized either by explanation or report. Most writers chose explanation to write the step grouping in the move participants, and few writers used report. The variance was caused by the different focus of the writers for paragraph can be identified as a complete unit of a cognitive genre, or a part of a unit of it; a paragraph can also contain two or more units of various cognitive genres. The number following the abbreviations of the cognitive genre types are the number of paragraphs identified as a specific genre type in a corresponding step of a move. For example, $R p 21$ in the first row of the column "cognitive genre" indicates that among all paragraphs in the steps location, sample size, and language-related features belonging to the move participants in the texts analyzed, 21 of them were identified as report.

The move data analysis, not always present in the methods sections in the reviewed texts, is presented in the table because it is essential for experimental RAs. If it is not included in the methods sections, it must be present in the results sections. The writers who used explanation to realize the step focused on the process and the means of grouping, whereas writers that employed report focused on the results of the grouping. As the organization of the information of a grouping process is different from that of its results, the writers used different cognitive genres to realize the varied communicative goals found in a step.

Because the choice of the cognitive genre reflects the communicative goals of the moves and steps, the much 
higher amount of explanation than report and recount indicated that the most essential communicative goal of the methods sections is to explain the methodological means adopted by scientists to achieve certain objectives.

\subsection{Cognitive Genres Employed in the Methods Sections of Corpus-Based RAs}

In the subcorpus of the journal articles of corpus-based research, explanation was found to occur most frequently in major moves and steps, followed by report. In total, 57 of 135 paragraphs $(42 \%)$ in the major steps of the major moves, were identified as explanation and $51(37 \%)$ were identified as report. Recount was rarely employed by the writers, and its frequency was only 13 (constituting approximately $10 \%$ of the total paragraphs of the corpus). A few instances of combined genres were identified; 10 instances of the combination of explanation and report with explanation as the major genre and 1 instance of the combination of report and explanation with report as the major genre were observed. Table 6 is a cross-reference table that summarizes the analysis of the cognitive genres of the major moves and essential steps in the methods sections of corpus-based RAs.

Table 6. Cognitive genres of the major moves and essential steps in the methods sections of corpus-based RAs

\begin{tabular}{|c|c|}
\hline Moves/Steps & Number of paragraphs identified as a cognitive genre \\
\hline \multicolumn{2}{|l|}{ Move 1: Providing information of the corpus } \\
\hline Describing quantity, source, and range of the linguistic data & Rp35 \\
\hline $\begin{array}{l}\text { Presenting text selection criteria (process)/or genre selection reasons/ or the } \\
\text { rationale of the corpus compiling }\end{array}$ & $\operatorname{Rp} 8 ; \operatorname{Exp} 6 ; \operatorname{Rec} 3 ; \operatorname{Rp}+\operatorname{Exp} 1$ \\
\hline \multicolumn{2}{|l|}{ Move 3: Elucidating data analysis procedure(s) } \\
\hline $\begin{array}{l}\text { Explaining the linguistic feature(s) to be analyzed OR the means to identify the } \\
\text { linguistic feature(s) OR a combination of the two }\end{array}$ & Exp16; Exp+Rp7; Rp4; Rec1 \\
\hline Introducing the tool(s) & Exp13; Rp4; Rec2 \\
\hline Specifying the procedure of the data analysis & Exp25; Rec7; Exp+Rp3 \\
\hline
\end{tabular}

Similar to the findings of the analysis of the cognitive genres in the methods sections of experimental RAs, the cognitive genres in a move or step of the methods sections of corpus-based RAs correlated with the communicative goals of the move or step. For instance, as the goal of the step the procedure of the data analysis in the move data collection was to provide information about the procedure adopted by a scientist, the major cognitive genres identified were explanation and recount, which organize the information pertaining to a procedure focusing either on means or the sequence. Similar to the authors who write the methods sections of experimental RAs, authors working on corpus-based RAs had limited choices for the cognitive genres when the communicative goals of a move or step were specified.

\subsection{Comparing the Results of the Analysis of the Cognitive Genres Employed in the Methods Sections of the Two Patterns of RAs}

Consistency is expected in the cognitive genres chosen to realize a specific move or step. As the communicative goals of moves and steps are specific and clear, the choices of cognitive genres employed to realize them are restricted. For instance, when a procedure must be described, the writers of both experimental and corpus-based studies use explanation or recount or a mixture of both to complete the task because both cognitive genres can organize information regarding the procedures taken in a research. However, if the focus of a move or step is explaining the measures intentionally adopted to achieve a desired goal, explanation is preferred over recount in presenting the means-ends relation. As explanation is the dominant cognitive genre in the methods sections, which provides the information of the process and the means adopted in a study, this suggests that most writers tended to focus on explaining why a procedure was taken

Overall, the results of the analysis of the cognitive genres of the methods sections indicated that it is nearly impossible to complete a methods section by using only one cognitive genre. The most frequently observed genre in the study was explanation, followed by report and recount. The added proportions of explanation and report and the paragraphs composed as a combination of these two equaled or even exceeded $90 \%$ of the total paragraphs in either the methods sections of experimental RAs or those of corpus-based RAs reviewed in the study. These findings are not consistent with those reported by Bruce (2008), who reported that the methods sections of most RAs consisted of one cognitive genre and that the major cognitive genre in the methods sections of social sciences and physical sciences RAs were recount and explanation, respectively. By contrast, the results of the current study indicated that most applied linguists did not complete the methods sections by using only one cognitive genre and that the most frequently identified cognitive genre in applied linguistics RAs was not 
recount. Explanation (followed by report) was the major cognitive genre in the methods sections of the reviewed RAs. The findings of the current study suggested that the cognitive genres used by applied linguists to complete the methods sections of their RAs were similar to those used by physical science scientists to complete the methods sections of their RAs.

\section{Conclusions}

Methods of research were found to be more influential than discipline is on determining the move structures of the methods sections of RAs. This finding has a pedagogical implication. Because most disciplines include experiments and surveys as their major research methods, as previous studies on move analysis probably described the move structures of experimental designs and survey methods, students conducting a research with a research design that is neither an experiment nor a survey may find the move structures suggested in the previous studies irrelevant. To provide useful guidance for such students, the methods sections for other research methods should be explored by EAP teachers and researchers. In addition to the move structures, cognitive genres, which realize the moves of an academic prose, are essential for academic writing. A writer usually needs more than one cognitive genre to realize the major moves and steps of the methods sections. Because the major cognitive genres with high frequencies in the methods sections of experimental and corpus-based RAs were the same, namely, explanation and report, mastering the writing skills of the two cognitive genres should be the focus of EAP teachers teaching academic writing to graduate students.

\section{References}

Biber, D. (1989). A typology of English texts. Linguistics, 27, 3-43. https://doi.org/10.1515/ling.1989.27.1.3

Bruce, I. J. (2005). Syllabus design for general EAP courses: A cognitive approach. Journal of English for Academic Purposes, 4(3), 239-256. https://doi.org/10.1016/j.jeap.2005.03.001

Bruce, I. J. (2008). Cognitive genre structures in methods sections of research articles: a corpus study. Journal of English for Academic Purposes, 7(1), 38-54. https://doi.org/10.1016/j.jeap.2007.12.001

Bruce, I. J. (2009). Results sections in sociology and organic chemistry articles: A genre analysis. English for Specific Purposes, 28(2), 105-124. https://doi.org/10.1016/j.esp.2008.12.005

Collin-Kies, S. (2014). Methods reported in ESP research articles: A comparative survey of two leading journals. English for Specific Purposes, 36, 27-34. https://doi.org/10.1016/j.esp.2014.04.001

Egbert, J. (2007) Quality analysis of journals in TESOL and applied linguistics. TESOL Quarterly, 41(1), 157-171. https://doi.org/10.1002/j.1545-7249.2007.tb00044.x

Glenhill, C. (2000). The discourse function of collocation in research article introductions. English for Specific Purposes, 19(2), 115-135. https://doi.org/10.1016/S0889-4906(98)00015-5

Kanoksilapatham, B. (2005). Rhetorical structure of biochemistry research articles. English for Specific Purposes, 24(3), 263-292. https://doi.org/10.1016/j.esp.2004.08.003

Kanoksilapatham, B. (2007). Rhetorical moves in biochemistry research articles. In D. Biber \& U. Connor (Eds.), Discourse on the move: Using corpus analysis to describe discourse structure (pp. 73-119). Amsterdam/Philadelphia: John Benjamins Publishing Company. https://doi.org/10.1075/scl.28.06kan

Kanoksilapatham, B. (2015). Distinguishing textual features characterizing structural variation in research articles across three engineering sub-discipline corpora. English for Specific Purposes, 37, 74-86. https://doi.org/10.1016/j.esp.2014.06.008

Knapp, P., \& Watkins, M. (2005). Genre, text, grammar: Technologies for teaching and assessing writing. Sydney: UNSW Press.

Lim, J. M. H. (2006). Method sections of management research articles: A pedagogically motivated qualitative study. English for Specific Purposes, 25(3), 282-309. https://doi.org/10.1016/j.esp.2005.07.001

Paltridge, B. (2002). Thesis and dissertation writing: An examination of published advice and actual practice. English for Specific Purposes, 21(2), 125-143. https://doi.org/10.1016/S0889-4906(00)00025-9

Peacock, M. (2011). The structure of the methods section in research articles across eight disciplines. The Asian ESP Journal, 7(2), 97-123.

Pilegaard, M., \& Frandsen, F. (1996). Text type. In J. Verschueren, J. O. Ostaman, J. Blommaert \& C. C. Bulcaen (Eds.), Handbook of pragmatics (pp. 1-13). Amsterdam: John Benjamins Publishing Company.

Swales, J., \& Luebs, M. (2002). Genre analysis and the advanced second language writer. In E. Barton \& G. 
Stygall (Eds.), Genre in the classroom: multiple perspectives (pp. 105-119). Mahwah NJ: Lawrence Erlbaum.

Swales, J. (1990). Genre Analysis: English for Academic and Research Settings. Cambridge: CUP.

\section{Notes}

Note 1. The lengths of the methods sections of the studied experimental RAs ranged from approximately 1400 to 3400. Most methods sections of corpus-based studies contained 1300 to 1400 words, with a few containing less than 600 words. The methods sections of the corpus-based studies tended to be shorter than those of the experimental RAs. Considering the varied lengths of the methods sections, the author included 35 texts instead of 30 in the subcorpus of the methods sections of the corpus-based studies to equilibrize the two subcorpora.

Note 2. A study with an experimental research design taking a data analysis approach of corpus analysis was categorized as an experiment. Corpus-based studies in this study refer exclusively to studies that do not have experimental designs.

Note 3 . In this study, a step occurred in more than 35\% of the texts in a subcorpus was defined as a major step.

Note 4. The unit used for the identifying cognitive genres was paragraph. A

\section{Copyrights}

Copyright for this article is retained by the author, with first publication rights granted to the journal.

This is an open-access article distributed under the terms and conditions of the Creative Commons Attribution license (http://creativecommons.org/licenses/by/4.0/). 